\title{
La herencia de las mujeres. Estrategias de transmisión patrimonial en las empresas ganaderas del medio oeste pampeano. Mediados del Siglo XX
}

\author{
Women heritage. Strategies of patrimonial \\ transmission in the livestock enterprises of Middle \\ West of La Pampa. Mid-twentieth century.
}

\author{
Selva Olmos \\ Instituto de Estudios Socio Históricos. \\ Facultad de Ciencias Humanas \\ Universidad Nacional de La Pampa \\ (Argentina) \\ seguirus@insert.com.ar
}

\section{Resumen}

Los estudios sobre la transmisión del patrimonio presentan un relativo desarrollo en la historiografía argentina, especialmente desde los años de 1990. Dichos estudios privilegiaron el espacio regional pampeano de fines del siglo XIX e inicios del XX. A tono con ellos, adherimos con aquella postura que afirma que las prácticas de transmisión del patrimonio en el agro pampeano dan cuenta de la coexistencia de múltiples mecanismos, de igualitarismo así como de exclusión. De este modo, resultan significativos los abordajes tendientes a analizar las lógicas familiares en la transmisión del patrimonio y las modalidades de reproducción.

Nos proponemos reflexionar sobre los mecanismos de transmisión del patrimonio de una familia de productores ganaderos del sur del entonces Territorio Nacional de La Pampa, la familia Russo, y trazar paralelismos con otros dos casos de la zona. De allí también nuestro interés se volcará a observar la herencia de las mujeres en estos entramados familiares pero también considerando su rol en las empresas ganaderas. Se trata de problematizar las relaciones de género que se daban dentro de las familias y en este caso, evaluando las experiencias de tres familias de una zona poco transitada por la historiografía local.

Palabras clave: Transmisión patrimonial - Familia - Empresas ganaderas - Herencia - Mujeres - Pampa

OLMOS, Selva, "La herencia de las mujeres. Estrategias de transmisión patrimonial en las empresas ganaderas del medio oeste pampeano. Mediados del siglo xx”, en Avances del Cesor, Año XI, No 11, segundo semestre 2014, pp. 155-173. 


\begin{abstract}
Studies on the transmission of heritage have a relative development in Argentine historiography, especially, since 1990. These are focused on the region of La Pampa in the late nineteenth century and early twentieth. In accordance with them, we share the idea that the practices of transmission of heritage in the agriculture of La Pampa prove the coexistence of multiple mechanisms, both egalitarian as exclusionary. In this way, those approaches that analyze family logics in the transmission of heritage and the methods of reproduction are very significant. We attempt to reflect on the transmission mechanisms of the heritage in a family of farmers in the South of the national territory of La Pampa -the Russo family- and draw parallels with two other cases in the area. We are also interested to observe the inheritance of women in these family networks and consider their role in livestock enterprises. We try to problematize gender relations existing within families (as in this case) assessing the experiences of three families, in a region poorly studied by the local historiography.
\end{abstract}

Key Words: Patrimonial transmission - Family - Livestock enterprises - Heritage - Woman - Pampa

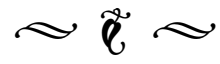

\section{Introducción}

La transmisión del patrimonio en el agro pampeano de fines del siglo XIX y principios del XX, siguió un modelo pautado en la coexistencia de una multiplicidad de prácticas que iban desde el igualitarismo hasta la exclusión de algunos hijos. ${ }^{1}$ De este modo,

1. Ejemplo de ello son los trabajos de: BJERG, María, OTERO, Hernán y ZEBERIO, Blanca, "De hijos excluidos a padres igualitarios. Prácticas de herencia de vascos y daneses en las tierras nuevas del sur bonaerense, 1870-1930", en: ZEBERIO, Blanca, BJERG, María y OTERO; Hernán (Compiladores) Reproducción Social y Sistemas de Herencia en una perspectiva comparada, Instituto de Estudios Históricos Sociales, Facultad de Ciencias Humanas, Universidad Nacional del Centro, Tandil, Buenos Aires, 1998, pp. 191-215; BJERG, María, Entre Sofie y Tovelille. Una historia de los inmigrantes daneses en la Argentina (1848-1930), Editorial Biblos, la historiografía patrimonialista, que tuvo su eclosión en nuestro país en los años de 1990, enmarcó sus estudios casi exclusivamente en esta zona donde las características particulares de la sociedad, con su herencia colonial primero y la afluencia extranjera después, dieron lugar a una miríada de estrategias familiares para reproducir su patrimonio. En la base, un marco legal liberal e igualitario debió convivir con un conjunto de estrategias y tradiciones familiares

Colección La Argentina Rural, Buenos Aires, 2001; y MORENO, José Luis, "La transmisión patrimonial de la pequeña propiedad agraria en la campaña del oeste bonaerense en el período de transición 1800-1870: un estudio de linajes familiares", en XIX Jornadas de Historia Económica, San Martín de los Andes, Neuquén, 13 a 15 de Octubre, 2004. En general, los estudios de este tipo han tomado un conjunto de varias familias, a veces de igual ascendencia etnográfica o de la misma región, para realizar comparaciones y hallar patrones de comportamiento similares. 
que redundaron en una multiplicidad de prácticas en la reproducción familiar. ${ }^{2}$

De este modo, resultan entonces significativos los abordajes tendientes a develar las lógicas familiares en la transmisión del patrimonio y las modalidades de reproducción. Sin embargo, en esta tarea, los estudios de género han merecido menor atención, quizá originado en la propia invisibilidad que gira en torno a la figura femenina a nivel de las fuentes. Desde ya que las perspectivas más tradicionales también han naturalizado la presencia dominante masculina en los ámbitos de poder y la historiografía aun no ha podido subsanar en parte esta situación. En las últimas décadas, sin embargo, algunos aportes arrojan luz sobre la situación de las mujeres en los mecanismos familiares de herencia pero en general su presencia se infiere de los relatos o quedan inmersas en sujetos históricos de mayor alcance como por ejemplo la institución familiar. $^{3}$

2. ZEBERIO, Blanca, “Tierra, familia y herencia en la pampa argentina. Continuidades y rupturas en la reproducción del patrimonio (siglos XIX y XX)", en Quinto Sol, Revista de Historia Regional, La Pampa, 2002, Año 6, No 6, Instituto de Estudios Socio - Históricos, Facultad de Ciencias Humanas, Universidad Nacional de La Pampa, pp. 129-151.

3. Véase, ZEBERIO, Blanca, BJERG, María y OTERO, Hernán (Compiladores) Reproducción Social y Sistemas de Herencia en una perspectiva comparada, Instituto de Estudios Históricos Sociales, Facultad de Ciencias Humanas, Universidad Nacional del Centro, Tandil, Buenos Aires, 1998; y GHIRARDI, Mónica, Matrimonios y familias en Córdoba 1700 - 1850, Centro de Estudios Avanzados, Universidad Nacional de Córdoba, Córdoba, 2004. El trabajo de ALVAREZ, Norberto y TORRICELLA, Andrea, "Estudios de género e historia de la familia. Una zona de investigación en construcción: balances y desafíos", en La Aljaba, Luján, 2009, V. XIII, No 13 analiza estos aspectos y realiza un recorrido teórico sobre el abordaje del género a nivel historiográfico. Luján, analiza estos aspectos y realiza un recorrido teórico sobre el abordaje del género a nivel historiográfico. Disponible en: http://www.
En este trabajo, y tomando como base un estudio de caso, el de la familia Russo, productores ganaderos ubicados en el sur de La Pampa durante la época territoriana, ${ }^{4}$ nos proponemos observar al interior de los mecanismos de transmisión del patrimonio de esta familia, y desde allí entablar algunas analogías con otras dos familias de productores del medio-oeste pampeano, si bien con otro nivel de explotación económica. En línea con ello, nuestra propuesta busca indagar en la situación de las mujeres de las familias, respecto de la herencia, pero también de las empresas ganaderas. ${ }^{5}$ Este trabajo es entonces una aproximación al problema de las prácticas patrimoniales a nivel de estas familias, una mirada que abre interrogantes sobre un tema escasamente transitado por la literatura académica local. En este sentido, y si bien el problema de las fuentes es un primer escollo a salvar, nos preguntamos, ¿Qué heredaban las mujeres? ¿Qué lugar recibían en la transmisión de los bienes? ¿Qué mecanismos se implementaban respecto a ellas? Pero

scielo.org.ar/scielo.php?script=sci_arttext\&pid=S1669$57042009000100004 \& \operatorname{lng}=$ es\&nrm=iso\&tlng=es

[Consulta: 22 julio 2014]

4. La actual provincia de La Pampa fue Territorio Nacional entre 1884 y 1951.

5. Estos casos han sido abordados en, OLMOS, Selva, "Criadores de los márgenes. Estrategias de acceso a la tierra, organización empresaria, producción y acceso a los mercados. El caso de la familia Russo, 18931939ca.", en Anuario 2005, Santa Rosa, 2006, Facultad de Ciencias Humanas; Universidad Nacional de La Pampa, Año VII, No 7; "Herencia, familia y tradición en el agro pampeano a inicios del siglo XX", en Actas de III Encuentro de Investigadores. Fuentes y Problemas de la Investigación Histórica Regional, Instituto de Estudios Socio - Históricos, Facultad de Ciencias Humanas, Universidad Nacional de La Pampa, Santa Rosa, 2008; y Vida productiva en las empresas ganaderas del medio oeste pampeano. Beca de Graduados, Instituto de Estudios Socio - Históricos, Facultad de Ciencias Humanas, Universidad Nacional de La Pampa, 2009 (Sin editar). 
también, nuestros interrogantes giran en torno a develar qué sucedía con esa herencia. Por ello, buscamos indagar en el rol que asumían las mujeres en la explotación agropecuaria. De allí también el interés en retomar las discusiones planteadas en torno al tema para el área núcleo bonaerense, al posibilitarnos localizar una serie de ejes que permitan trazar paralelismos entre las prácticas de los actores sociales de ambas zonas y a la vez, la intención es realizar un aporte a la historiografía local sobre la que no hay investigaciones de este tema. Creemos que abordar los estudios a nivel de las estrategias familiares da cuenta de las razones que se esconden detrás de determinadas decisiones. Los cambios generacionales, las creencias, los intereses individuales y grupales, los vínculos personales, son todos aspectos que surgen desde esta mirada. ${ }^{6}$ Además, la originalidad de cada uno de los casos nos puede permitir plantear el comportamiento de un modelo general de empresa en el medio - oeste pampeano.

De allí también que las fuentes para estudiar la transmisión del patrimonio reportarán entonces distinta naturaleza, a saber, historias de vida, protocolos notariales, juicios de sucesión, mensuras, títulos de propiedad, boletos de compra venta, documentos contables, hipotecas, entre otros aportes. A nivel de las metodologías, se hace necesario además un análisis de los mecanismos de transmisión a través de dos o tres generaciones familiares. La reconstrucción de las trayectorias familiares a lo largo de varios ciclos permite sobre todo observar los trasplantes y mutaciones de las tradiciones de

6. Un estudio sobre el proceso de formación de un patrimonio familiar así como su transmisión en, REGUERA, Andrea, "Familia, formación de patrimonios y transmisión de la tierra en Argentina. Los Santamarina en Tandil (1840-1930)", en GELMAN, Jorge, GARAVAGLIA, Juan Carlos y ZEBERIO, Blanca (Compiladores) Expansión capitalista y transformaciones regionales. Relaciones sociales y empresas agrarias en la Argentina del siglo XIX, La Colmena, Buenos Aires, 1999. 158 los inmigrantes, sus adaptaciones a la nueva realidad y la incidencia en los hijos naturales argentinos.

\section{Sobre nuestros interrogantes}

Las investigaciones centradas en el abordaje de las estrategias familiares, y con una reconocida trayectoria en nuestro país, han ponderado un enfoque basado en la microhistoria, y es en esta línea que enfocamos nuestra investigación a través de los estudios de caso pero insertos en un contexto diferente al área modelo bonaerense, el de La Pampa territoriana de principios de siglo XX. Esta perspectiva, más atenta a los sujetos, nos permite entender la razonabilidad de las prácticas productivas y organizativas y hallar los principios de inteligibilidad que determinaban tales comportamientos. Entonces, partimos de la familia, de su dinámica, como una vía de acceso para iluminar problemas diversos. Ahora bien, como lo expresa Zeberio, $^{7}$ en el contexto de una sociedad nueva y con abundancia de tierras, como era el espacio pampeano de fines del siglo XIX e inicios del $\mathrm{XX}$, las prácticas de transmisión no pueden ser tampoco analizadas únicamente desde la familia y su patrimonio, sino que es necesario articular las estrategias familiares con el marco legal, las instituciones jurídicas, las redes de intermediarios, y las tradiciones familiares, entre otros aspectos. ${ }^{8}$ Sin embargo, creemos

7. ZEBERIO, Blanca, “Tierra, familia y herencia...”, Op. Cit.

8. Los aportes de Blanca Zeberio, entre ellos: "Derechos de familia, propiedad y herencia. Codificación y discursos jurídicos en el siglo XIX”, en Jornadas de Investigación y debate "La Argentina rural. Una reelectura de los clásicos", 4 y 5 de Noviembre, Universidad Nacional de Quilmes, Quilmes, 2004; “Los hombres y las cosas: cambios y continuidades en los Derechos de propiedad (Argentina, Siglo XIX)", en Quinto Sol, Santa Rosa, 2005, Facultad de Ciencias Humanas, Universidad Nacional de La Pampa, 
que aquí hay un punto que aun merece ser considerado y es en relación a la perspectiva de género. Un estudio sobre las estrategias familiares en la transmisión del patrimonio debe también centrarse en el papel que juegan las cuestiones de género: ¿Qué lugar ocupan las mujeres en la explotación? ¿Cuál en la familia? Generalmente, y aquí debemos hacer una autocrítica, se piensa a la familia como un sujeto histórico único, como una totalidad; lo que Alvarez y Torricella, denominan una "neutralización sexual" de la familia. ${ }^{9}$ No hay por parte de la literatura una problematización de la masculinidad o de la femineidad como una construcción. En general, los análisis abordan las familias como si todos los sujetos tuviesen el mismo pensamiento y se dejan de lado los abordajes de las generaciones, el género, los posicionamientos, las diversidades dentro de una misma institución familiar; o bien quedan en la mera descripción. En igual sentido, tampoco se trata de establecer dualidades maniqueas entre víctimas y victimarios, o de naturalizar las diferencias de sexo. Según exponen estas mismas autoras, existe toda

No 9 disponible en: http://www.scielo.org.ar/pdf/quisol/ n9-10/n9-10a06.pdf [Consulta 22 julio 2014]; analizan especialmente la transición jurídica de la Colonia a la República en nuestro país en relación a la familia, la propiedad y la herencia. También SENOR, María Selva, "La institución de herederos en la sucesión abintestato: Transformaciones en la concepción de familia y herencia. Buenos Aires durante la primera mitad del siglo XIX", en Quinto Sol, Facultad de Ciencias Humanas, Universidad Nacional de La Pampa, Santa Rosa, 2004, No 8, disponible en: http://ojs.fchst.unlpam.edu.ar/ ojs/index.php/quintosol/article/view/698 [consulta: 22 julio 2014]; indaga en los discursos jurídicos pero para la primera mitad del siglo XIX en Buenos Aires. En esa línea, también es relevante el trabajo de MAYO, Silvia, "Familias rioplatenses tardocoloniales: conflicto en torno a la herencia y al patrimonio", en GHIRARDI, Mónica (Compiladora) Cuestiones de familia a través de las fuentes, Centro de Estudios Avanzados, Universidad Nacional de Córdoba, Córdoba, 2005, pp 59-89.

9. ALVAREZ, Norberto y TORRICELLA, Andrea, "Estudios de género...", Op. Cit. una tradición literaria que ha abordado las estrategias de reproducción familiar para la época colonial en Hispanoamérica, asentadas meramente sobre el ejercicio del poder masculino. Y el eje estuvo puesto en el mantenimiento del patrimonio como una vía para conservar el prestigio y el honor familiar; de ahí que las mujeres aparecen como víctimas de ese entramado. Davidoff y Hall, en su estudio sobre la clase media inglesa provincial de los siglos XVIII y XIX, dejan perfilar su postura a esta cuestión tan arraigada de lo privado como opuesto a lo público. ${ }^{10}$ Los hombres de clase media que aspiraban a una posición social con capacidad de mando sobre los demás, estaban insertos en una estructura familiar que les brindaba la ayuda femenina esencial para esta aspiración. Y así la mujer aparecía como un socio de facto en el negocio familiar. Para los autores, masculinidad y femineidad son los productos concretos de un tiempo y un espacio. Se construyen continuamente. De allí que, y a tono con renovados estudios sobre el papel de género y la historia familiar, debemos problematizar las relaciones de género que se daban dentro de las familias y en el caso que nos ocupa, evaluando las experiencias de de las mujeres Russo, Coya y Lernoud. ${ }^{11}$ Como lo expresa Scott, tomar la historia de la mujer como objeto de investigación es darle historicidad a la experiencia de ser mujer.

10. DAVIDOFF, Leonore y HALL, Catherine, Fortunas familiares. Hombres y mujeres de la clase media inglesa 1780-1850, Editorial Cátedra, Madrid, 1994. Disponible en:

http://books.google.com.ar/

books?id=SZZ2hCETGmoC\&printsec $=$ frontcover\&hl=es\&ource=gbs_ge _ summary_r\&cad=0\#v=onepage\&q\&f=false [Consulta: 22 julio 2014].

11. Sobre las nuevas perspectivas, véase; GIRBAL BLACHA, Noemí, "La historiografía argentina: enfoques microhistóricos regionales para la macrohistoria rural del siglo XX (1980-1999)", en Estudios Interdisciplinarios de América Latina y el Caribe, 2001, V. XII, No 2; ALVAREZ, Norberto y TORRICELLA, Andrea, "Estudios de género...”, Op. Cit. 
En función de nuestros problemas y en el marco de una tradición legal de carácter igualitario, nos preguntamos: ¿Se cumplía la norma legal para con todos los miembros de un grupo familiar a la hora de heredar? ¿Heredaban lo mismo mujeres y hombres? En este sentido, en tanto se trata de productores rurales medios, una cuestión a observar es el tipo de familia; no era lo mismo, a la hora de legar, el comportamiento de una familia arrendataria que los parámetros seguidos por un estanciero con grandes propiedades rurales. Hasta la existencia o no de un testamento nos está diciendo algo. Por ello no podemos desatender el vínculo que los productores rurales tenían con la tierra. Esta, más allá de constituir un bien material o económico, era además un capital simbólico determinado por el uso social que se le atribuía. La tierra contribuye a la conformación de una identidad, vincula a los individuos con un entorno cultural determinado, y su posesión puede implicar prestigio y poder sobre los otros, o bien su carencia puede significar sujeción y vulnerabilidad. $\mathrm{Y}$ es en el marco familiar donde se transmiten los principales rudimentos culturales, así la tierra se constituye en herencia material pero también en herencia cultural. Si los bienes familiares constituyen la identidad social de la familia, ¿las prácticas de transmisión buscan entonces mantener el nombre de la familia ligado a la tierra? ¿Esto fue siempre así? Entonces, ¿quién hereda los derechos agrarios? ¿Cómo se articulan los criterios de distribución del patrimonio con el rol de cada integrante de la familia? Y en ese sentido, resultaría importante en principio, reflexionar sobre los modos de tenencia y las formas de transmisión, especialmente cuando no hay propiedad. Y en igual medida, observar el papel de género en los patrones de herencia seguidos en el agro pampeano decimonónico problematizando las lógicas familiares; ¿cuáles eran los mecanismos seguidos con las mujeres? ¿Qué rol jugaban ellas en las decisiones?
Estos interrogantes nos conducen a su vez a la empresa, ¿Cuál era el papel de las mujeres en las explotaciones? Los momentos de transmisión del patrimonio se correspondían con el cambio en el gerenciamiento de la empresa. Por ello, observar este punto es fundamental porque está en los propios mecanismos de herencia la respuesta sobre el rol femenino dentro de la familia pero en especial dentro de la explotación agropecuaria. Así, el vínculo género - explotación es otra ventana desde donde mirar estas empresas agropecuarias que en una coyuntura capitalista cambiante y vulnerable generaban estrategias para adaptarse a los vaivenes de los mercados. Los casos analizados pueden ser una base para enriquecer el amplio abanico de experiencias que se sucedieron en el agro pampeano de mediados del siglo XX.

Para una mejor organización de los contenidos hemos decidido estructurar el artículo en dos partes. En la primera, presentaremos el caso de las familias Russo, Lernoud, y Otero Coya, a través de un breve recorrido por los mecanismos de estos productores para acceder a la tierra y la organización de las empresas agropecuarias en base a la orientación productiva de la zona. En segundo lugar, nuestra mirada se centrará en las formas de reproducción social y herencia estableciendo algunas comparaciones entre los casos expuestos.

\section{Los criadores del medio oeste pampeano}

La incorporación de la actual Provincia de La Pampa a la economía nacional y mundial fue el resultado del desplazamiento de la frontera bonaerense hacia el Oeste, a raíz de la expansión ganadera; y dicho proceso concluyó con la campaña militar de 1879. En forma inmediata comenzó la dinámica de ocupación y 


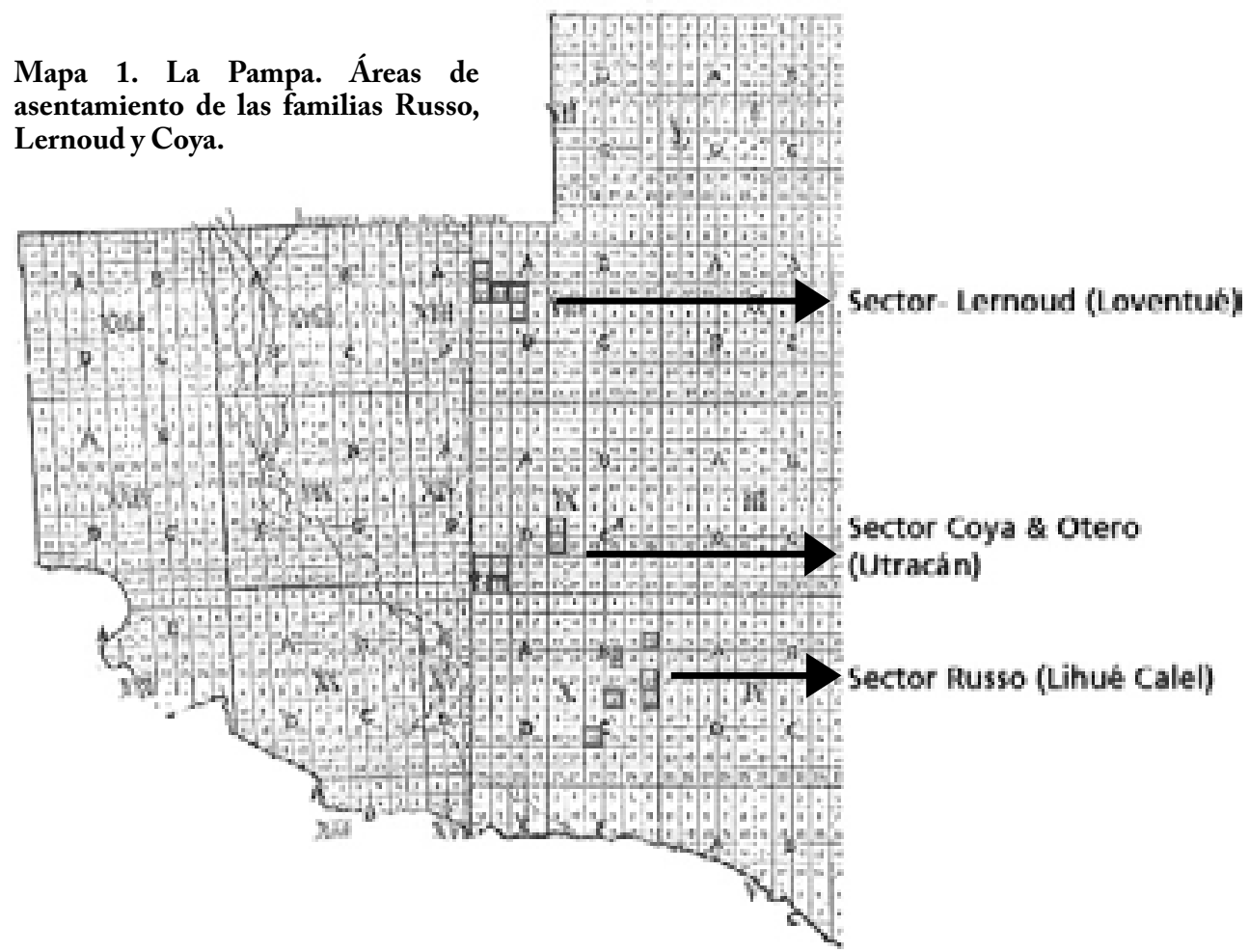

poblamiento efectivo del espacio bajo el marco de una economía pastoril donde se valorizaron los establecimientos rurales en el marco de una demanda de tierra en ascenso. Detrás de estos procesos se combinaron diferentes formas de ocupación y estrategias organizativas en un universo signado por la diversidad. Así lo dejan ver las historias de vida de las familias: Russo, del Noveno Departamento (luego Lihue Calel); Lernoud, del Séptimo Departamento (luego Loventué); y Coya, del Octavo Departamento (Utracán). ${ }^{12}$ Los

12. La primera división administrativa del Territorio corresponde a 1888 y definía nueve departamentos que coincidían con las secciones catastrales. En 1904 se redefine dicha organización y La Pampa se casos son sólo un dechado de un conjunto de experiencias, que en una época muy temprana llevaron adelante el proceso de re-poblamiento y puesta en producción capitalista de una zona "marginal". En ese contexto, era el negocio de la lana la base de la expansión económica de todo el grupo y en función de éste, las familias desplegaron mecanismos para acceder a la tierra, acrecentarla, organizar la producción y la mano de obra; acceder a los mercados; y transmitir su patrimonio.

estructuró en base a dieciséis departamentos. Por último en 1915, un nuevo ajuste dividió al Territorio en veintidós departamentos y se cambió la numeración por denominaciones de raíz indígena. 


\section{Tres casos bajo la lupa}

\section{La familia Russo}

La historia de esta familia en Argentina comenzó a tejerse en la década de 1880 con el arribo de Macario Russo desde Italia. Había nacido en 1856 en Episcopia, provincia de Potenza, donde tenía un hijo, Nicola. Aquí se ocupó como alambrador en una estancia de la zona de Sauce Grande, en la provincia de Buenos Aires y contrajo enlace con Juliana Legarralde, quien tenía una hija de soltera, María. El camino seguido por la familia Russo en el acceso a la tierra fue quizá el de muchos inmigrantes que al no contar con un capital inicial partieron de una situación de asalariado posiblemente ocasional, para transformarse luego en socio menor de la estancia donde trabajaba. El hecho es que esta situación de "medieros" fue el punto de partida de una acumulación de capital que les permitió transformarse en arrendatarios en el sur de La Pampa, zona con otras características productivas pero que seguramente estaba al alcance de sus posibilidades en esa época. En 1893, el matrimonio se asentó en el lote 3, fracción C, de la X Sección pampeana, propiedad de Pablo Pedro Pourtalé. ${ }^{13}$ En este campo nacieron sus otros siete hijos: Macario, José, Julián, Sebastián, Juan, Pedro e Isaura. Durante la segunda década del siglo XX y a medida que los hijos varones arribaban a una edad de 15 o 16 años, Macario arrendaba un campo en las cercanías y los encomendaba al cuidado de una "punta" de ovejas. De esta forma, a la locación del lote 3 , se sumaron los lotes 5 y 12 de la misma fracción C, y los lotes

13. Pourtalé fue uno de los principales beneficiarios de las donaciones de tierras efectuadas por la Caja de Crédito Público de 1881 a 1884 en los Territorios Nacionales. Recibió 105.000 hectáreas en La Pampa, según Mensuras Generales, X 346-17, Archivo de la Dirección General de Catastro.

162
15 y 25 de la fracción $B$, de la misma sección $\mathrm{X} .{ }^{14} \mathrm{Al}$ respecto, debemos afirmar que todos los predios fueron arrendados por dos generaciones manteniéndose por varias décadas los mismos propietarios y arrendatarios, hasta los años de 1940 en que los propietarios iniciaron el proceso de venta. Esta situación resultaría coherente en una zona de propietarios rentistas donde ambas partes dependían de los vínculos con los intermediarios. Pero las fuentes familiares también evidenciaron arrendamientos por la misma época (segunda década del siglo XX) en el sudoeste bonaerense en las zonas de Vitícola y Coronel Dorrego, cercanas a Bahía Blanca. Así, por medio de una estrategia que combinaba trabajo familiar, diversificación espacial y capitalización en hacienda, este productor buscó rentabilizar su capital a la vez que asegurar un patrimonio a su descendencia, si bien no en tierras en la zona. $\mathrm{Su}$ orientación en materia de inversión en esta primera época fue en propiedades urbanas en la ciudad de Bahía Blanca: entre 1907 y 1920, según el Juicio de Sucesión, adquirió en esa ciudad seis lotes de chacra, cinco viviendas, un terreno y una quinta. Este tipo de inversión, muy temprana por cierto, posiblemente se deba a la imposibilidad de arriesgar capital en inversiones mayores pero igualmente evidencia la prudencia en materia económica, pues si bien no reportarían cuantiosos beneficios eran una colocación segura. La memoria oral de sus descendientes da cuenta de la negativa de Macario a invertir en tierras, sin embargo, en 1925 y pocos meses antes de fallecer, adquirió 1.485 hectáreas de campo en el Partido de Villarino, provincia de Buenos Aires. Esta adquisición marcaría el nivel de acumulación logrado en la década de 1920 pero también, creemos que existieron otros factores no netamente económicos que inclinaron la balanza hacia la decisión de comprar tierras.

14. Un lote equivale a 10.000 hectáreas, en una zona donde la unidad económica es de 2.500 hectáreas. Véase, OLMOS, Selva “Criadores de los márgenes...”, Op. Cit. 
Entre ellos cabría mencionar el respaldo de las casas consignatarias, depositantes de los beneficios del trabajo familiar; y en especial, el cambio generacional determinado por los hijos que buscaban arraigarse y asegurarse un patrimonio. Entonces, a pesar de su postura, la acumulación de capital que adquirió en calidad de arrendatario y criador en La Pampa, supo invertirla en acrecentar el número de tierras arrendadas así como en propiedades urbanas y rurales en otra zona. Se trata de un ejemplo quizá diferente a los comúnmente bosquejados por la literatura pero que refleja la flexibilidad de empresa así como la dinámica de los procesos productivos que acontecieron en el agro pampeano.

Esta nueva lógica, y a la par del cambio

\section{Imagen 1. Familia Russo, 1916.}

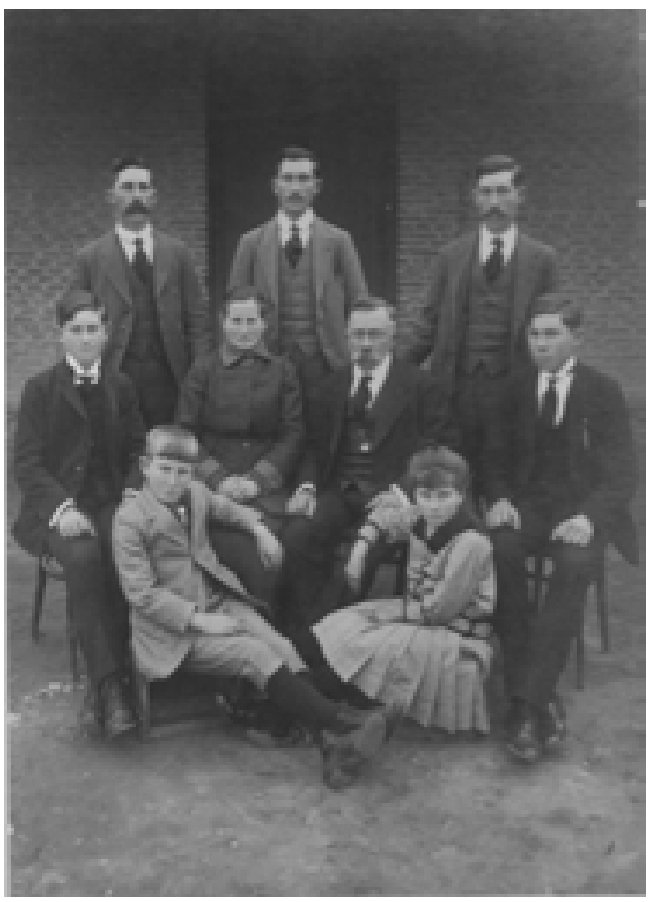

generacional, quedó evidenciada tras el fallecimiento del padre de familia en 1925. Ese año los hijos varones conformaron la sociedad "Russo Hermanos", y en 1928 adquirieron 5.000 hectáreas del lote 18, fracción $B$, sección $X$, campo denominado "La Isabel" por 70.671,20\$ nacionales. Así, a partir de una estrategia de acumulación en conjunto pudieron convertirse en propietarios en su zona. Según las fuentes, para los años de 1920, los Russo producían ovejas para lana y ganado en pie en el sur de La Pampa y ganado vacuno y lanar en la provincia de Buenos Aires. Esta combinación y diversificación espacial y productiva les habría permitido sortear avatares de coyuntura económica y a la vez, lograr un nivel de acumulación. En ese sentido, resulta importante también destacar que las decisiones no eran tampoco arbitrarias sino que dependían de un contexto donde el peso de la incertidumbre era determinante, y es por ello que consideramos que más que maximizar beneficios, estos productores intentaban minimizar riesgos.

En 1929 los hermanos disolvieron la sociedad y uno de ellos, Julián, que en ese año se casó con Delia Francisca Cao, tomó posesión del campo, abonando arrendamiento a los otros cinco hermanos socios en tanto les iba comprando sus partes, y pudo acceder a la totalidad del predio en 1943. Macario (h), por su parte, vendió la quinta parte pro indivisa que tenía, a su hermano Pedro, por $\$ 20.000$ $\mathrm{m} / \mathrm{n} .{ }^{15}$ Continuó arrendando el lote $3(10.000$ hectáreas) y a inicios de la década de 1930 entabló una sociedad de hecho con el señor Ricardo López, vecino de la zona, por partes iguales. Al fallecer López en 1937, la sociedad continuó con su esposa, Francisca Subilibia, con quien Macario Russo se casó en 1938. A diferencia de la sociedad de los hermanos

15. Archivo del Registro de la Propiedad Inmueble, (en adelante ARPI), Minutas de escrituras, T. CXVIII, Folio 118 , 
Russo que compraron un campo, ésta se mantuvo como arrendataria del mismo lote 3 del cual los integrantes compartían el cincuenta por ciento de los gastos y beneficios. En 1942 se convirtieron en propietarios de la estancia "La Madrugada" (lote 15, fracción D, sección II) en Anguil y continuaron arrendando las 10.000 hectáreas del lote 3 a las herederas de Pourtalé a quienes se lo compraron en $1948^{16}$. José Russo, compró en 1932 la quinta parte que le correspondía de "La Isabel" a su hermano Sebastián por $11.000 \$$, reuniendo así 2.000 hectáreas de su propiedad, por las cuales recibía un canon de arrendamiento de su hermano Julián. A éste vendió dicho predio en 1943. ${ }^{17}$ Pero José, desde 1925 explotaba el campo que la familia poseía en Villarino, "La Isaura". Juan, en tanto, también recibió pagos por el arrendamiento de su parte en el lote 18 de su hermano Julián hasta 1943 en que se lo vendió. En tanto, continuó como arrendatario de las 10.000 hectáreas del lote 5 (fracción $\mathrm{C}$, sección $\mathrm{X}$ ), el cual compró en 1948 a las mismas sucesoras de Pourtalé. ${ }^{18}$ En 1956 lo vendió y se trasladó a la zona de Santa Rosa donde compró 1.200 hectáreas de un establecimiento llamado "La Catin" del Departamento Capital. Pedro, si bien no conformó la sociedad de hermanos, en 1929 compró la quinta parte de "La Isabel" (lote 18, fracción $\mathrm{B}$, sección X) a su hermano Macario y se la dio en arrendamiento a Julián, a quien se la vendió en $1943 .{ }^{19}$ En tanto, continuó como arrendatario y compró en 1941 a Matilde Dolores Giraldez, 2500 hectáreas del lote 15, fracción B (ángulo Noreste); y en 1945, a la

16. ARPI, Minutas de escrituras, T.CDXXII, Folio 59, Finca No 581999.

17. ARPI, Minutas de escrituras, T. CXVIII, Folio 120; y T. CCXCIII, Folio 29.

18. ARPI, Minutas de escrituras, T. CCCLIII, Folio 48, Finca No 57350.

19. ARPI, Minutas de escrituras, T.CXVIII, Folio 118 y T. CCXCIII, Folio 29.
Compañía Anan Crédito y Finanzas S.A., 2.500 hectáreas (ángulo Sudeste) del mismo lote 15 (fracción $\mathrm{B}$, sección $\mathrm{X})^{20}$, las cuales vendió en 1946 y pasó a desempeñar otras actividades como administrador de estancias. Sebastián, quien estuvo mucho tiempo como arrendatario de "La Aguada" (lote 12, fracción C, sección X), vendió en 1932 su parte del campo a José y de allí en más desarrolló diferentes actividades.

\section{La Familia Lernoud}

La historia de esta familia en Argentina se inició con la llegada de los hermanos Amand y Emilio Lernoud como representantes de la casa exportadora francesa Masurel Fils a fines de la década de 1880. Amand se instaló en Montevideo, Uruguay y contrajo enlace con María Augé con quien tuvo siete hijos: Julio, Eduardo, María Ester, Fernando, Pablo, Marcelo y Margarita, nacidos entre 1891 y $1905 .{ }^{21}$ Esta posición les permitió a los hermanos adquirir tierras en los nuevos territorios pampeanos. Emilio Lernoud, compró entonces un campo en la zona de Victorica que bautizó “San Emilio” y Amando, en 1898 adquirió 7.457 hectáreas del lote 22, fracción A, de la sección VIII por 54.600 pesos, que denominó "La Morocha". No obstante, Lernoud continuó adquiriendo tierras y hacia 1900 poseía más de 17.000 hectáreas

20. ARPI, Minutas de escrituras, T. CCCXXXII,Folios 182 Finca No 24739; Folio 183, Finca No 24738; y Folio 184 , Finca № 24740.

21. LASSALLE, Ana María y LASSALLE, Paula, "Querido padre, te escribí esta mañana...". La metamorfosis de la identidad en las tarjetas postales de Eduardo Lernoud (1913-1914)", en DI LISCIA, María Silvia, LASSALLE, Ana María y LLUCH, Andrea (Co-editoras) Al Oeste del paraíso. La transformación del espacio natural, económico y social en La Pampa Central (siglos XIX - XX), Instituto de Estudios Socio Históricos, EdUNLPam, Miño y Dávila, Buenos Aires, 2007. 
en la misma zona, y compró además otro establecimiento en Pellegrini, provincia de Buenos Aires, para la actividad de invernada. De este modo, combinó el negocio rural (cría e invernada) en distintas zonas del agro pampeano con la administración del comercio lanero para la exportación en Montevideo.

En otro orden y a juzgar por las fuentes, este empresario ejerció un férreo control de su explotación a pesar de residir en ella sólo temporalmente. Las continuas misivas al mayordomo de turno así lo revelan y en ellas hallamos además, evidencia de la multiplicidad de tareas que se desarrollaban en la estancia. Esta empresa logró combinar la propiedad y explotación directa con el arrendamiento de campos vecinos, el servicio de pastoreo a terceros y la posibilidad de seguir invirtiendo en tierras nuevas. Además, el nivel de la

\section{Imagen 2. Amand Lernoud, esposa e hijos.}

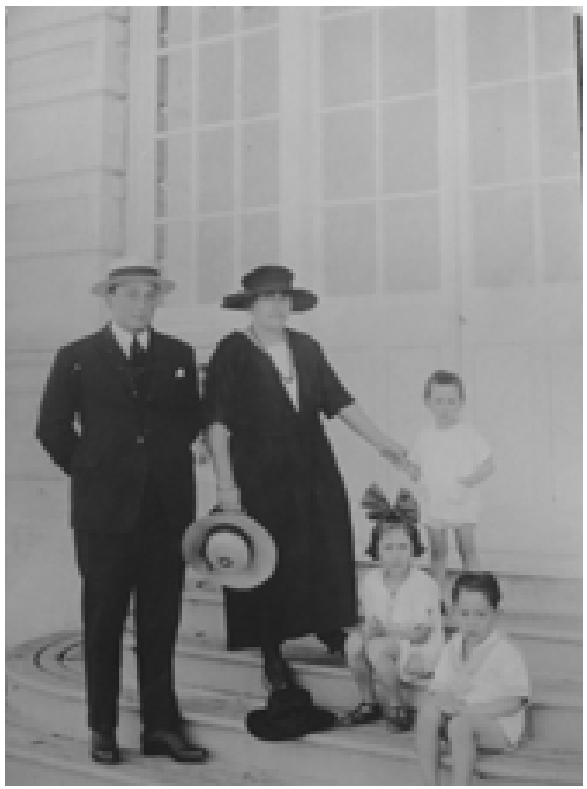

explotación les permitía acceder directamente a los mercados de Buenos Aires, diferente a los Russo, por ejemplo.

\section{Familia y sociedad: los Coya - Otero}

La familia Otero es quizá una de las más emblemáticas de la zona de General Acha, tanto por su trayectoria económica como por el prestigio social que han adquirido a lo largo del tiempo. No contamos con fuentes directas de los Otero pero sí de la familia Coya, directamente emparentada con esta. El entramado familiar en los orígenes, vía las sociedades comerciales, hace de esta familia una fuente de riqueza invalorable para su análisis, si bien aquí los expondremos sucintamente y a sólo efecto de entablar comparaciones con el caso de los Russo.

Sebastián Benito Coya Alonso nació en la aldea española de Llares, perteneciente al Municipio de Piloña en la Provincia de Asturias, el 21 de Marzo de 1883. Allí contrajo enlace con Aurora Fresno, también oriunda de esa región y tuvieron a su primer hijo, Emilio, en 1908. Ese mismo año, el 12 de Septiembre, llegó a Argentina dejando en su tierra a su familia y alentado por su primo hermano Ramón Otero Coya, propietario de la casa de comercio "La Asturiana" ubicada en el lote 8 de la fracción A, sección X del Departamento pampeano de Lihue Calel, con quien vino a trabajar. ${ }^{22}$ En 1909 llegaron su esposa e hijo. Como lo relató el propio Sebastián a la revista La Moderna en 1938, "trabajé en La Asturiana de repartidor; fui cocinero, durante un año, en Agua Blanca. En 1917 compré ovejas y me establecí en Casa de Piedra, lote 20; estuve unos tres años en las sierras; hice mucha plata, a puro trabajar, en esas cuarenta leguas

22. El parentesco entre ambos deviene al ser el padre de Sebastián, José Coya, hermano de Ramona, madre de Ramón Otero Coya. 
que sujetaba en mis puños y en mi voluntad de acero". ${ }^{23} \mathrm{El}$ hecho es que Sebastián Coya manejaba los campos que en sociedad tuvo con la familia Otero: “...desde El Veraneo, unas diez leguas más o menos de aquí [General Acha], con veintidós leguas a mis órdenes, los lotes 6, 15, 19, 20, 22 y dos leguas del $21 \ldots .{ }^{24}$ En La Pampa nacieron también sus otros hijos: Celina Aurora (1910); Palmira (1914); Francisco José (1918); Máxima (s/d) y María Magdalena (s/d). En el año 1920 viajó a España para educarlos en Colunga pero regresó y a partir de allí comenzó a trabajar de forma asociada con Ramón Otero Coya. Según su relato, en 1923 entabló sociedad con Francisco Otero Portas, hijo de Ramón; luego Francisco pasó a trabajar en la casa comercial La Moderna de General Acha y quedaron en la sociedad Sebastián y Ramón con un capital de $\$ 150.000$ cada uno. Al fallecer Ramón en 1930 siguió cuidando de los intereses de su esposa Justina Portas, ahora su socia, heredera y cesionaria de sus hijos. Sin embargo, los archivos notariales, expresan que el 28 de Junio de 1929, Sebastián Benito Coya y Ramón Otero Coya constituyeron la sociedad civil, agrícola ganadera "Coya y Otero", por tiempo indeterminado, para la compra - venta, cría $y$ refinamiento de ganados en general, con un capital de trescientos mil pesos moneda nacional aportados por los socios por partes iguales, representado por un campo ubicado en el lote 6 de la fracción D, sección Novena de este Territorio, cuya extensión era de 10.000 hectáreas. Posteriormente, y según escritura del 29 de julio de 1929, la sociedad adquirió un terreno de chacra en la mitad Este del lote 8 , fracción C, sección Novena, designado en el plano de mensura de la Colonia Lía, compuesto por una superficie de 115 hectáreas, 99 áreas y
92 centiáreas. Al fallecer Ramón Otero Coya en 1930, heredó entonces su esposa Justina y pasó a ser socia de Coya, aunque al parecer en lo formal ello recién se legalizó en 1940. Una vez disuelta la sociedad "Coya y Otero" se formó otra bajo el rubro "Sebastián Coya y Compañía”, que sesionó entre 1940 y 1951. Además, Justina Portas vendió a la sociedad "Otero Hermanos y Compañía", que dirigían sus hijos, el "Haber" que en condonación con Sebastián Coya le había correspondido en la disolución de la sociedad y con el que la sociedad "Otero Hnos. y Cía." concurrió a la formación de la nueva sociedad "Sebastián Coya y Compañía”. Más allá de este juego de asociaciones, debemos ver entonces en el caso de Coya un ejemplo de familia - empresa, pero donde la familia se extiende a parientes más lejanos y con el respaldo de una sólida empresa comercial. Además, el caso de Sebastián Coya es un excelente ejemplo de movilidad económica donde desde una tarea de peón pudo convertirse en criador de ovinos, y luego, a través de su participación en sociedades consecutivas, obtener un ascenso social y económico que incluyó además la propiedad de la tierra. Y la base de esa posibilidad estuvo dada por la pertenencia a un grupo familiar determinado. Más tarde, su primogénito, Emilio Coya, fue el encargado de continuar y asegurar la prosperidad en el negocio ganadero, destino signado por nuevos cambios. En 1951, luego de la disolución de la firma "Sebastián Coya y Cía.", se formó otra bajo el rubro "Sebastián Coya e hijos", lo que significó la separación de Coya con los hermanos Otero y por ende del patrimonio que poseían en conjunto. Así, Coya recibió el lote 6, campo llamado "La Aurora" que sus descendientes mantienen en producción hasta la actualidad.

23. La Moderna, Revista comercial, social y literaria. Órgano oficial de la Casa Otero Hnos. y Cía. T. III., Año V, General Acha, La Pampa, 1938.

24. Ibídem. 


\section{Prácticas de transmisión del patrimonio familiar}

\section{Los Juicios de Sucesión de Macario Russo y Juliana Legarralde}

Macario Russo falleció el 4 de Junio de 1925 en Bahía Blanca, y lo sobrevivieron su esposa Juliana Legarralde, siete hijos legítimos (dos de ellos menores de edad), y una hija, María, que portaba el apellido materno. Catorce días después, fueron publicados en la prensa local los edictos correspondientes. $\mathrm{El}$ juicio se inició con un "poder" otorgado al consignatario Mario Olaciregui "para obrar en nombre y representación de todos los Russo (mayores y menores) para seguir hasta su completa terminación el juicio sucesorio de Macario Russo"; y Juliana Legarralde, juró en Acta como "administradora provisoria de los bienes de la sucesión”. ${ }^{25}$ De acuerdo a la fuente, los bienes se inventariaron en tres distritos diferentes: Bahía Blanca, Villarino, y La Pampa; y consistían en tierras (urbanas y rurales), útiles de campo, semovientes, boletos de marca y señal. ${ }^{26}$

25. Archivo Departamental de Tribunales, Juicio de Sucesión de Macario Russo, Legajo 45 P, No 10856 (190 fojas), Año 1925, juez: Martín Esandi, Bahía Blanca.

26. Bienes en Bahía Blanca: seis lotes de chacras, inscriptos el 11/12/1907, por un valor de $\$ 1960$. Una fracción de terreno con edificación de 1019 metros cuadrados de superficie. Lote 10 de la quinta 232 (con edificación), de 249 metros cuadrados, calle 25 de Mayo No 40, inscripto en La Plata el 02/09/1920. Una fracción de terreno (con edificación), superficie: 1.019 metros cuadrados, inscripto el 03/12/1907, valor $\$ 14000$. Una fracción de terreno, manzana 38 (con edificación), 217 metros cuadrados, inscripto en La Plata el 04/08/1920, bajo el No 767. Casa de dos plantas en calle Alsina. Valor: \$26040; y dos casa en calle Buenos Aires 355 y 365 (adquiridas en fecha 04/08/1920 y 02/09/1920, de 249 y 257 metros cuadrados, respectivamente) cuyo valor era de $\$ 42000$. Además, 3209 semovientes (584 vacunos; 2580 lanares; y 45 yeguarizos). Los datos son "copia de ficha en
El Juicio de Sucesión refleja una distribución igualitaria de los bienes donde la esposa percibió la mitad de éstos, materializados en: dos viviendas y lotes de terrenos en Bahía Blanca, el campo de Villarino, 8218 ovinos, 141 vacunos; 25 equinos; 2 automóviles Ford; 1 sembradora; y 16 boletos de señal en la Provincia de Buenos Aires. Pedro e Isaura, los hijos menores, recibieron cada uno una casa en la misma ciudad. En tanto los demás hijos recibieron semovientes, títulos de propiedad (boletos de marca y señal) y útiles. No se detalla en la fuente los bienes que adquirieron individualmente, sólo la herencia en general discriminada en ambas provincias. En total, 2000 ovinos, 1038 vacunos, 216 equinos, 9

Bahía Blanca, 01/06/1924”. Nota: Las propiedades “Lote 10 de la quinta 232" y la "fracción de terreno, manzana 38 ", reconocen una hipoteca de $\$ 40.000$ a favor de la casa consignataria Zonco y Cía. Bienes en el Partido de Villarino: Nueve fracciones de campo que forman parte del Lote 62, sección Cuarta "Caldén-Guazú", en total, 1485 hectáreas (adquiridas en fecha 26/01/1925 a Petrona Heguilor Vda. de Bordeu) por un valor de $\$ 65800$; 2615 semovientes (2000 ovinos; 556 vacunos y 59 yeguarizos) valuados en $\$ 49520$; 9 boletos de señal, expendidos por la Municipalidad de Bahía Blanca a nombre de Macario Russo en el año 1924 (\$90); 1 boleto de marca, inscripto en la Oficina de Marcas y Señales de La Plata el 11/08/1915 en el Libro 8, folio 16. Bienes en La Pampa: 9029 semovientes (8218 ovinos; 622 vacunos; 180 yeguarizos; y 9 mulas), valor: $\$ 72745$; dos automóviles Ford usados (\$600); una chata de cuatro ruedas (\$200); una Break de cuatro ruedas $(\$ 180)$; tres zorras de pértigo (\$150); dos arados de reja (\$150), una sembradora en mal estado (\$100); una escardadora de alfalfa (\$100); un rastrillo ( $\$ 100) ; 16$ boletos de señal, expendidos por el Noveno Departamento, Juzgado de Paz de La Pampa, año 1921, a nombre de Macario Russo; 2 boletos de marca a nombre de Macario Russo por la Gobernación de La Pampa. Capital en entidades bancarias: Banco de la Nación Argentina, \$195. Total del Haber Hereditario: en Bs As \$204.335; en La Pampa \$ 74.547. Total: \$278.882. Deudas: \$192.707 (al Banco de la Nación; a Petrona Heguilor Vda. de Bordeu y al consignatario Zonco y Cía.). Fuente: expediente sucesorio de Macario Russo. 
mulares, herramientas, boletos de señal y marca. Así, los acuerdos para repartirse las partes entre los hermanos varones mayores fueron externos a la norma jurídica y quedaron en el nivel de lo privado. En definitiva recibieron lo que estaban ya explotando consistente en su mayoría en ovinos, además de perpetuos vínculos con los propietarios de los campos. $\mathrm{Y}$ son ellos los que luego forman la sociedad Russo Hnos.

El principal escollo que la familia se prestó a resolver una vez encaminado el juicio de sucesión, fue la cancelación de algunas deudas. El campo de Villarino había sido adquirido en el mes de enero de 1925, por el que asumieron deudas con la propietaria, Petrona Heguilor de Bordeu, y la casa consignataria Zonco y Cía. Desconocemos si la deuda con el Banco Hipotecario correspondía al mismo predio. La firma consignataria, se aseguró el préstamo con hipotecas de dos propiedades que los Russo poseían en la ciudad de Bahía Blanca. La muerte, al parecer sorpresiva (según los testimonios) del padre de familia en el mes de junio del mismo año, implicó para sus deudos la necesidad de esgrimir una solución al problema del pago del campo. Entonces, según consta en el juicio de sucesión, la familia pidió al juez autorización para vender esas dos propiedades, con el fin de pagar la deuda contraída por la adquisición de dicho inmueble. El juez autorizó a Juliana a proceder. Ambas eran inversiones que la familia había realizado en 1920, y utilizadas como casas de alquiler por las que percibían rentas. Desconocemos los intersticios de las ventas, pero por el posterior juicio de sucesión de Juliana, una de las viviendas no se vendió en este momento sino en 1941. Tampoco conocemos cómo saldaron al fin las deudas y qué ocurrió con la otra propiedad. Una respuesta, quizá, puede hallarse en los propios convenios con Zonco y Cía., pues la firma además de acreedora era depositaria de partidas de frutos de algunas explotaciones de la familia. Más allá de la resolución del problema en sí, debemos destacar el hecho de que las viviendas hipotecadas fueron adjudicadas a Juliana. Posiblemente era ésta también una estrategia interna conducente a salvaguardar la herencia de los hijos. Llama nuestra atención que la firma comercial Lanusse y Olaciregui, con la que más trabajaba la familia en Bahía Blanca, no figura en el juicio, ni como acreedora ni como deudora. Creemos que una posible vía de pago de las deudas haya estado en los depósitos que los Russo tenían en esta casa consignataria o en el acceso al crédito por parte de ésta. De manera que no tuvieron la necesidad imperiosa de descapitalizarse vendiendo propiedades que a su vez les reportaban rentas.

El otro problema que avizoramos refiere a la explotación del campo de Villarino que heredó la esposa. En la práctica, fue José Russo el que desde el inicio se asentó allí, y años después, al fallecer su madre, heredó legalmente la explotación. ${ }^{27}$ Ahora bien, ¿Por qué sólo José heredó el campo? Él intervino en la sociedad entablada entre los hermanos al morir el padre con el fin de convertirse en propietarios en $\mathrm{La}$ Pampa, pero al igual que el resto vendió su parte para que Julián accediera al total. Esa quinta parte fue en definitiva una inversión y aseguro para comprar el campo de Villarino que era el verdadero interés de este productor. Hallamos así mismo, que efectuaba pagos sucesivos a su madre vía los consignatarios. Entonces, lo que realizaba José era el pago en sí del propio campo. Y la estrategia de legar la

27. "ha quedado virtualmente terminado el juicio sucesorio, acompañándose a la presente los títulos de propiedad e hijuela respectiva de adjudicación a favor del heredero José Russo y Legarralde de la fracción de campo ubicada en el partido de Villarino, inscripta en el Registro de la Propiedad de La Plata". (Extracto del Juicio de Sucesión de Juliana Legarralde. La fuente es un resumen del Juicio original, elaborado por el abogado interviniente Dr. Bernardo V. Vila en Bahía Blanca, 14 de Octubre de 1941, momento en que finalizó el proceso). 
madre un bien importante a un sólo hijo era una manera de evitar pérdidas de beneficios a través de transferencias de compra - venta. Sería un ejemplo de cómo los conflictos y sus resoluciones quedaban en el nivel de lo doméstico y las instancias formales de los juicios de sucesión eran la fachada final de procesos ya resueltos.

En el caso de Sebastián y a instancias del Juicio de Sucesión de Juliana, éste había solicitado su parte de la herencia con anterioridad a la instancia legal y así lo refiere la fuente: "Para establecer el importe que corresponde a cada uno de los herederos, con prescindencia de vuestro hermano Sebastián, quien antes de ahora recibió su parte que por adjudicación le hubiera correspondido". ${ }^{28}$ Entonces, en el Juicio de Sucesión de Juliana los beneficiarios fueron, al igual que en el de Macario, siete herederos. Mientras en 1925 María Legarralde fue excluida del reparto; en 1941, ella percibió su parte de manera equitativa a sus hermanos (en dinero), y Sebastián no figura entre los herederos por haber percibido su parte con anterioridad. Como vemos, las prácticas de herencia conllevaban la convivencia de tendencias igualitarias con diferentes grados de exclusión y compensación. Esto significaría que dichos mecanismos eran entonces dinámicos $\mathrm{y}$ cambiantes en función de cada lógica familiar.

\section{Estrategias familiares de herencia en perspectiva comparada: las mujeres en la transmisión formal del patrimonio y el peso de la herencia inmaterial}

Las trayectorias de las familias antes bosquejadas dan cuenta que en materia legal las mujeres heredarían según lo estipulaba la ley, es decir, en un marco de igualdad respecto a los hombres. En especial los casos de Lernoud

28. Ibídem. y Otero Coya, ambos propietarios de tierra, reflejan, según los documentos judiciales, la igualdad en el reparto patrimonial. Sin embargo, es necesario ir más allá y observar las prácticas y estrategias que encerraban cada una de estas decisiones. ${ }^{29}$

Uno de estos mecanismos era el de la exclusión. En el caso de los Russo, no todos los hijos heredaron lo mismo. Al fallecer el padre, y como dicta la norma, la mitad de los bienes correspondieron a su esposa, entre ellos la mayoría de las propiedades urbanas, la única propiedad rural, un buen número de hacienda, vehículos, y algunos boletos de marcas. En cuanto a los hijos, los menores heredaron propiedades en Bahía Blanca. Esta estrategia podría cumplir la doble función de "protección", a partir de un bien que puede considerarse menos expuesto al deterioro y más seguro en términos de renta, y la posibilidad de mantener unido el patrimonio por un tiempo mayor. ${ }^{30}$

Pero, y como lo expresan los autores, el mecanismo de compensación, era también una forma de exclusión. ${ }^{31} \mathrm{Si}$ bien no tenemos registros, los testimonios nos hablan de que a

29. En el caso de los Lernoud contamos con el Expediente Sucesorio de Amand (1942), pero sólo se hallan en él los títulos de propiedad donde dan cuenta que todos los hijos legaron partes iguales de los campos. No tenemos registros orales de esta familia ni fuentes para épocas posteriores a 1914 .

30. CANEDO, Mariana, "Tierra sin gente y gente con tierra. La dinámica del acceso y de la transferencia de la tierra en una zona de colonización temprana de la campaña de Buenos Aires (Los Arroyos, 1600-1850)", en ZEBERIO, Blanca, BJERG, María y OTERO, Hernán (Compiladores) Reproducción Social y Sistemas de Herencia en una perspectiva comparada, Instituto de Estudios Históricos Sociales, Facultad de Ciencias Humanas, Universidad Nacional del Centro, Tandil, 1998, pp.83119.

31. BJERG, María, OTERO, Hernán y ZEBERIO, Blanca, “De hijos excluidos...”, Op. Cit., pp. 204-205. 


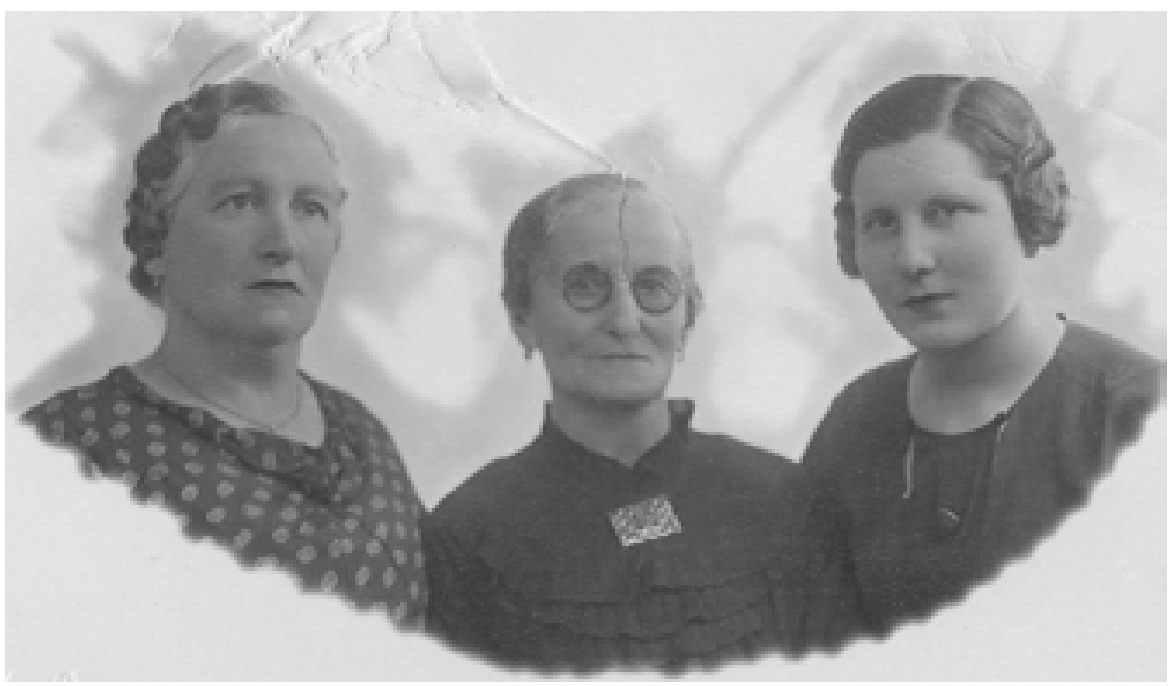

Imagen 3. Mujeres Russo, María, Juliana, Isaura

las mujeres se las compensaba con muebles, joyas, dinero, obras de arte, $u$ otros bienes que además de un valor económico reportaban para la familia un valor tradicional y afectivo. Esa herencia inmaterial que circulaba por fuera de la norma legal y de los documentos, creemos representaría un peso importante a la hora de observar el volumen de los bienes heredados. Muchas veces, heredar una joya o una pintura original, era preferible a otro bien patrimonial. El problema, según nuestra mirada, es que en el caso de las mujeres y también de los hijos menores, este mecanismo de compensación las alejaba de la explotación agropecuaria. Este podría ser el mecanismo que se utilizó con Isaura pero no parece haber sido el mismo para su madre, Juliana. Aunque ella tampoco explotó directamente el campo que heredó sino que se lo legó a un hijo. Justina Portas, si bien heredera de los negocios de su esposo, en tanto viuda, depositó en sus hijos la gerencia de la sociedad. Ahora bien, ¿Quién tomaba las decisiones? Por eso, y si bien no estamos a la altura de profundizar aún el tema porque requeriría de mayores indagaciones, sobre todo vía la memoria oral, otra vez, acordamos con la perspectiva planteada al inicio, de que habría que observar a nivel individual, en las propias mujeres, y no sólo como decisiones familiares. Creemos sí, que el imaginario respecto a la poca capacidad de gerenciamiento femenino atravesaba el conjunto del agro pampeano. Las actividades rurales son una construcción donde ha primado siempre el género masculino, de ahí que casi "naturalmente" las mujeres dejen su lugar, aun siendo propietarias, al manejo de hijos, esposos o cuñados, sus tierras. Entonces, podríamos aventurar lo que Bjerg, Otero y Zeberio definen como un sistema de igualdad masculina, en el que las mujeres no fueron excluidas del derecho de la propiedad pero sí del derecho a la gestión de la explotación. ${ }^{32}$

32. Ídem, p. 214. 
No se trataría así de herederas residuales sino de supuestos preestablecidos culturalmente sobre la poca capacidad femenina para el gerenciamiento rural. ${ }^{33} \mathrm{La}$ autora habla de un poder de decisión no efectivo en las mujeres, a modo de percepción cultural, que las forzaría a delegar en un varón de la familia su herencia en tierras.

Los demás hijos Russo, recibieron bienes para la explotación ganadera (hacienda; maquinarias y enseres; y boletos de marca y señal) pero ningún inmueble. En cambio, en el juicio de sucesión de Juliana (1941), el campo de Villarino fue legado a su hijo José. Cabría pensar que éstos eran entonces mecanismos para asegurar la continuidad del patrimonio. Por otra parte, Macario (h), si bien como arrendatario, a la muerte del padre continuó asentado en el lote originario (lote 3 ) desde donde mantenía la centralidad de la empresa. La elección de un sucesor, en este caso para la distribución de un bien y para la herencia del rol de jefe del grupo doméstico, tenía por objeto asegurar la continuidad del patrimonio familiar.

Al observar el camino seguido por los hermanos Russo a la muerte del padre, consideramos posible que se trataría de un caso donde en tanto arrendatarios y poseedores de semovientes y útiles, el principal activo de los hijos varones, mayor peso habría adquirido la herencia de mecanismos informales para la obtención de tierra a buen precio o la posibilidad que los propietarios de las tierras les continúen

33. CÓRDOVA PLAZA, Rocío, "Acceso de las mujeres a la tierra y patrones de herencia en tres comunidades ejidales del centro de Veracruz", en Relaciones, México, invierno, 2003, El Colegio de Michoacán, Zamora, V.XXIV, No 93, pp.179-212. Disponible en: < http:// etzakutarakua.colmich.edu.mx/relaciones/093/pdf/ Ros\%C3\%ADo\%20C\%C3\%B3rdova\%20Plaza.pdf> [Consulta: 22 julio 2014]. arrendando. ${ }^{34}$ Entonces, la red informal de vínculos construida por el padre de familia a lo largo de su vida en la zona, fue el recurso al que apelaron los hijos una vez fallecido éste y utilizando su nombre como garantía. En palabras de Dérouet y Goy, los Russo habrían conformado así una "dinastía de arrendatarios" o lo que es igual, una "patrimonialización del arrendamiento" al sucederse por varias décadas en los mismos campos. ${ }^{35}$ A la vez, los hijos de Macario al formar la sociedad de hermanos, reiniciaron un ciclo de acumulación y ampliación de tierras como una estrategia de organización de una explotación en la fase de expansión, y luego cada uno de ellos inició lo que Zeberio define como ciclo de acumulación y ampliación individual. ${ }^{36}$ Los Russo, no sólo continuaron arrendando los mismos campos sino que en 1928 compraron otro en la misma zona, lo que podría ser interpretado como una estrategia tendiente a mantener unido el patrimonio.

34. ZEBERIO, Blanca, "El estigma de la preservación. Familia y reproducción del patrimonio entre los agricultores del sur de Buenos Aires, 1880-1930", en BJERG, María y REGUERA, Andrea (Compiladoras) Problemas de la Historia Agraria, IEHS, Universidad Nacional del Centro, Tandil, 1995, p. 166. Además, debemos llamar la atención sobre el arrendamiento, pues no es considerado por el Derecho como patrimonio y por ende su transmisión no se sujeta a las exigencias de la partición igualitaria que impone la ley.

35. DÉROUET, Bernard y GOY, Joseph, "Transmitir la tierra. Las inflexiones de una problemática de la diferencia", en ZEBERIO, Blanca, BJERG, María y OTERO, Hernán (Compiladores) Reproducción Social..., Op. Cit., pp. 15-50.

36. ZEBERIO, Blanca, "El estigma de la preservación...”, Op. Cit., p. 169. En sus estudios sobre los chacareros propietarios del sudeste bonaerense, el arriendo cobró una marcada importancia como mecanismo para volver a organizar la explotación familiar luego de haber sido afectada por una partición entre muchos descendientes donde las parcelas resultantes apenas alcanzaban el límite de rentabilidad. La metodología consistía en alquilar tierras a la propia familia (generalmente hermanas o madre) y a bajo costo. 
A instancias de las estrategias seguidas por los Russo en cuanto a la transmisión de sus bienes y tomando en cuenta su situación de arrendatarios - propietarios en una zona marginal, donde resultaba importante mantener el patrimonio tanto como los vínculos con los propietarios de los campos que alquilaban, quizá deberíamos aceptar la aseveración de Dérouet y Goy de que es necesario, para comprender tales prácticas, razonar en términos de explotación (o incluso de "actividad") más que en términos de patrimonio puramente. ${ }^{37}$ Además, nunca o casi nunca, se recibía una herencia que garantizara una vida cómoda, según los parámetros de cada época. ${ }^{38}$ Sin embargo, la capacidad individual, y lo que Zeberio denomina como "entramados familiares" solían ser el factor de dependencia del éxito de la reproducción familiar al facilitar la mediación en el acceso a los mercados de tierra, comercialización o crédito. ${ }^{39}$ Esta situación, nos lleva a pensar en que la familia actuaba de acuerdo a una lógica congruente con lo que acontecía a nivel de prácticas de herencia en el agro pampeano. Al igual que su correlativo bonaerense, el medio - oeste del Territorio de La Pampa evidenciaba una diversidad de prácticas de herencia (igualitarismo, exclusión, elección de un sucesor), con una relativa libertad para delinear con antelación y por fuera de la norma jurídica algunos mecanismos de transmisión, y la posibilidad de apelar al pragmatismo y "sentido común" a la hora de proyectar un sendero a seguir en cuanto a los mecanismos de transmisión. Por esto, sumamos nuestros hallazgos a la vertiente

37. DÉROUET, Bernard y GOY, Joseph, "Transmitir la tierra...", Op. Cit., p.23.

38. MORENO, José Luis, "La transmisión patrimonial..., Op. Cit.

39. ZEBERIO, Blanca, “Tierra, familia y herencia...", Op. Cit., p. 143.

172 que encuentra la posibilidad de delinear un modelo de reproducción familiar en la base del capitalismo pampeano. Tanto los productores del agro bonaerense que tratan los autores mencionados, así como los del medio - oeste pampeano, más allá de la diversidad de prácticas existentes, buscaban asegurar la continuidad del patrimonio familiar en el tiempo, y en ese sentido, el éxito no se hallaba sólo en el presente inmediato sino en que sus empresas continuaran integradas más allá de la vida del progenitor.

\section{Conclusiones}

Los mecanismos de herencia en el ámbito pampeano de mitad de siglo XX eran el resultado de una combinación entre la norma y la práctica, y entre los legados coloniales y las tradiciones que en materia de herencia traían los inmigrantes a estas tierras. En ese camino, cada familia, y según su posición respecto a la tierra y al capital, elaboró un juego de estrategias para transmitir sus bienes y reproducirse socialmente. Más allá de la familia, cada integrante es importante en este entramado porque hallamos que hay diferentes factores que cuentan a la hora de definir estas estrategias: la condición de género, la edad, la progenitura, los estudios, entre otros.

Los mecanismos elegidos por la familia Russo, detonante de nuestra investigación, combinaron el igualitarismo con la exclusión, si se tiene en cuenta que las hijas fueron compensadas con propiedades urbanas o dinero. Pero desconocemos el nivel de decisión de ellas. Hubo sí, un arreglo en vida del padre para el reparto de los bienes en consonancia con la actividad ganadera al asignar tempranamente una porción de tierra en arriendo más una majada de ovejas a los hijos varones, las propiedades urbanas a los 
hijos menores (entre ellos la hija), y el campo de propiedad a la esposa. A pesar del recurso a la sucesión ab-intestato, el reparto de los bienes estuvo pautado de antemano. Así, uno de los hermanos heredó el establecimiento de Villarino con una venta previa acordada al interior de la familia. En congruencia con ello, otra estrategia fue la del hijo o hijos elegidos ya sea para la dotación de un bien como para ejercer el rol de gerenciamiento. En ese punto es que nos preguntamos por el gerenciamiento femenino y los casos dan cuenta de un alejamiento de las mujeres respecto a las explotaciones. Sin embargo, sí las hallamos herederas de lo que denominaríamos como una herencia inmaterial con mucho peso a nivel de la familia.

Al indagar sobre las prácticas patrimoniales de los productores ganaderos pampeanos, este trabajo, desde una reconstrucción empírica, trajo al escenario una multiplicidad de mecanismos tejidos al interior de las familias que van más allá de lo estipulado por la norma legal, situaciones de inclusión como de exclusión. En ese marco, nuestros interrogantes buscaron acercar el foco a la familia pero también a la empresa y desde allí observar estas prácticas considerando que todos los hijos tienen igual derecho. Ahora bien, ¿Dichas prácticas abrigaron situaciones de conflicto? Aun dentro de cada familia, ¿Los mecanismos se ejercían sin discusión? ¿Qué posibilidades existían para una mujer que heredaba tierras en una zona marginal? En ese sentido, resulta importante también destacar que las decisiones de estos productores no eran tampoco arbitrarias sino que dependían de un contexto donde el peso de la incertidumbre era determinante. Estos son sólo algunos de los tantos interrogantes que aún quedan por transitar en este camino de observar la dinámica y racionalidad empresarial de los productores ganaderos, sean éstos propietarios o no. Con seguridad, otros trabajos podrán continuar en dicha senda y observar estos interrogantes para otras zonas y épocas; o abrir nuevas vetas de análisis a partir de nuestras evidencias. Esperamos, no obstante, que la posibilidad de haber realizado un abordaje de tipo empírico a través de las trayectorias familiares, ilumine en parte todo el entramado de experiencias que se suscitaron en el agro pampeano de mediados del siglo $\mathrm{XX}$, a la vez que plantee nuevos problemas y desafíos.
Recibido: 10/03/2014 Aceptado: 08/09/2014 